\title{
Vocational Teaching-Learning through the Eyes of Undergraduate Vocational Students in Malta: A Qualitative Exploratory Study
}

\author{
Alison Said* \\ Department of Educational Research, County South, Lancaster University, \\ Lancaster, United Kingdom
}

Received: 28.08.2017; Accepted: 27.02.2018; Published: 26.04.2018

\begin{abstract}
The purpose of this study is to develop a deeper understanding of the teaching qualities of effective lecturers that vocational students desire, students assessment preferences and preferred learning environments. This study gives a voice to higher vocational students as it is important for vocational educators to learn what attracts students to effective learning.

Due to the inquiry's exploratory nature, an interpretivist approach was used, and a constructivist grounded approach using qualitative data was adopted. A purposive approach to multiple case study selection was used where the unit of analysis was a higher vocational student. The perceptions and expectations of vocational undergraduate (EQF level 6) students in two disciplines (applied science and engineering) were explored, to identify what may constitute good practice. A total of ten participants from two different institutes within the vocational university college agreed to be interviewed. Semi-structured and photo-elicitation interviews were applied. In addition, the Powerful Learning Environments (PLEs) Framework was used as a preliminary tool to aid in the decision-making process for data collection. Iterative analysis was used for the semistructured interviews, whilst a constant-comparative method was used for the photoelicitation image analysis.

Overall, the expectations and preferences between both groups were very similar. Results show that students expect to be taught by interactive lectures that relate theory to practice that will prepare them for the job. Formal lectures including presentations were the least favoured. Regarding teaching qualities, students expect approachable and
\end{abstract}

\footnotetext{
${ }^{*}$ Corresponding author: a.said@lancaster.ac.uk
}

ISSN: $2197-8646$

http://www.ijrvet.net 
understanding lecturers who provide concrete industrial examples. Assessment preferences included home based assignments and research projects. The preferred learning environment is in line with most characteristics of the Powerful Learning Environment.

Evidence shows that there is no particular difference between a higher vocational student and a higher education student. Implications for the enhancement of students' learning processes are discussed and recommendations for further research are elaborated.

Keywords: VET, Vocational Education and Training, Higher Vocational Education, Teaching Quality, Student Expectations, Photo-Elictitation, Learning Environments

\section{Introduction}

More studies need to explore vocational students' expectations and opinions of quality teaching. Despite a growing number of studies on the effectiveness of teaching and quality within the vocational education context (e.g. Misbah et al., 2015; Placklé et al., 2014), the higher vocational education context is under-represented. Therefore, the research reported here aims to respond to this gap in the literature by contributing to the practical knowledge of quality teaching within a Maltese higher vocational education institution. The purpose of this study was twofold and its main research questions are:

1. What are the students' perceptions of effective vocational teaching in terms of:

a) Lecturers' personality characteristics;

b) Lecturers' behaviour and knowledge;

c) Students' needs and expectations;

d) Assessment/coursework preferences?

2. What are the students' preferred learning environments?

Strengthening vocational education within the European Union is of utmost importance, and this could be achieved by implementing a cohesive, vocationally oriented pedagogic-didactic approach. Competence-based education within Vocational Education and Training (VET) systems is the leading paradigm for educational innovation (Biemans et al., 2004). The term 'competence' can be described as the combination of knowledge, skills and attitudes needed to perform well in a particular situation within a profession (Verhaeghe et al., 2011). The career of vocational students must be central to this approach. Thus, in order for students to develop competences and develop their career, learning programmes must include a 'community of practice' as an essential learning arrangement. This results in constantly shifting the boundaries of institutions for organised learning around the careers of vocational students. Having such a learning arrangement might lower student dropout rates since students will find their learning experience attractive and relevant. This is considered to be effective teaching as it ensures that the surface approach to learning is replaced by deeper learning, which consists 
of analysing, developing, creating and demonstrating work. This will eventually lead to a population having higher qualification levels. In fact, the main aim of policy makers is to reduce dropouts by strengthening vocational education and ensuring a widely employable population (de Bruijn, 2004).

According to Billett (2001), vocational education curricula should include pathways of participation in social practice. Vocational expertise ('knowing in practice') can only be developed if students have the opportunity to access and participate in practice. Where social practice is central and enacted in curricula, students are made aware of their own role in learning. This learning approach results in two basic principles: emphasis on a school-based and initial education, and the perspective of career as a guiding principle. This implies that both principles cannot be reconciled on every point. The work of vocational educators is fundamentally changed due to such new learning arrangements, which result in dilemmas and practical tension experienced by these educators.

To support students' learning, educators benefit from knowing and understanding what students perceive of teaching and learning (Dahl, 1995); according to Hill (1995) and Sander et al. (2000), student expectations are a valuable source of information. Therefore, students' voices need to be heard; acting upon them might increase quality in teaching within vocational education and training (VET). In addition, students can be informed by the respective universities of realistic expectations from lecturers (Hill, 1995). Quality in teaching is also reported to be enhanced when the vocational undergraduate curriculum is evaluated and redesigned according to the students' expectations as well as the requirements of careers (Dwyer, 2001). Telford and Masson (2005) also point this out, where the perceived quality of educational services depends on students' expectations and values. Such studies reflect the importance of understanding students' expectations and perceptions within higher vocational education.

This paper begins by reviewing the literature related to the above-mentioned foci towards effective teaching and learning within both the higher and vocational education context, as well as learning environments' characteristics. De Bruijn and colleagues' (de Bruijn \& Leeman, 2011; de Bruijn \& Overmaat, 2002; de Bruijn et al., 2005) conceptual framework related to powerful vocational learning environments is adopted to look at students' ideas of preferred learning environments. Semi-structured and photo-elicitation interviews are applied with 10 students from two different disciplines (applied science and engineering) to develop a deeper understanding of their expectations and perceptions. The study uncovers constructs that underlie higher vocational students' expectations, and argues that there is no particular difference between a higher vocational student and a higher education student. This paper concludes with a discussion of the research findings, limitations together with future work. 


\section{Teaching Quality in Higher Education and Vocational Education}

\section{Lecturers' personality characteristics}

The lecturer and their personality play a major part on the students' learning and their preferences. According to Trammell and Aldrich (2016), the characteristics of personality can be understood as innate within the lecturer regardless of subject content and level of education. The personality of the lecturer reflects who the person is regardless whether lecturing in class or outside.

One very important attribute of a lecturer described by students is empathy (Jaasma \& Koper, 1999). The majority of other studies also support this claim; indeed, empathy was consistently a desired characteristic of lecturers by students (Anderson, 2000).

Other studies have also suggested that students prefer enthusiastic lecturers (Anderson, 2000; Sander et al., 2000). The willingness to answer to students' questions was also preferred, including being flexible and adaptable to all students (Voss et al., 2007). Faranda and Clarke (2004) have also reported that students are mostly satisfied with respectful lecturers who build a rapport.

Such characteristics represent a broad spectrum of communication practices that lecturers use to meet their own goals and students'. The following is a discussion pertaining to the competence and expertise of lecturers.

\section{Lecturers' behaviour and knowledge}

Students are still unsatisfied with the programme if their lecturers lack organisational skills, even if they have ideal personality characteristics and are knowledgeable in their field (Shea et al., 2003). Pepe and Wang (2012) also report that students highly value organizational skills even when it comes to the seated positions within class. They describe that an organised seating position helps in the communication of knowledge between lecturers and students.

Apart from having well designed courses and organised lecturers, students look for prompt feedback on their work from their respective lecturers. Hounsell (2003) describes that when students have a sense of what they are doing right and wrong, they learn more quickly and efficiently. Avoiding giving feedback on time allows for the wrong information to be held, and in effect, will be more challenging for students to correct themselves. According to Hara (2000), student's frustration and level of anxiety can increase due to lack of feedback, especially with online courses.

Voss et al., (2007) declared that the overall student satisfaction and student learning depends on lecturer's expertise and competence, together with their teaching skills and pedagogy used. 'Teacher immediacy' (Andersen, 1979) and 'relevance' (Frymier \& Shulman, 1995), together with 'credibility' (McCroskey \& Young, 1981) are all behavioural characteristics that students look out in their lecturers. Behaviours such as verbal and nonverbal immediacy are associated with positive affective learning (Witt et al., 2004), student motivation (Frymier, 1994) and participation (Rocca, 2009).

Ustunluoglu (2017) stated that although the number of studies on the effectiveness 
of quality teaching within higher education is growing, reports by international agencies still show that more work is needed with regard to meeting expectations in teaching quality, specifically to lecturers' application of pedagogical knowledge. Universities should develop quality teaching by enhancing pedagogy, support for student learning and providing continuous education for faculty members (Henard, 2010). Hatakenaka (2006) highlights that there are still lecturers who use outdated methods in the classroom and take only into consideration 'what to teach' rather than 'how to teach'. Thus, pedagogic research is of outmost importance to develop lecturers within both higher education and vocational education. Student preferences will be examined in the following section.

\section{Students' needs and expectations}

Evaluations of teaching appropriateness together with expectations (Houser, 2005) have been one way in which scholars examined the goals and needs of students within the classroom. Houser (2005) reported that both traditional and non-traditional students experienced some discrepancies between what they expect from their lecturers and what they actually get. One reason for these differences is the fact that both lecturers and students have differing views about what students want and need in order to succeed. The primary fact is that researchers and lecturers are still not sure of the lecturer behaviours and characteristics students desire. Researchers, particularly in the vocational section can understand more the comparative importance of teaching variables and thus provide ongoing implications regarding how lecturers should behave, by determining students' preferences and how students prioritize certain behaviours and characteristics. Goldman et al. (2017) have addressed how students prioritize instructional behaviours and characteristics with varying resources. Their findings indicated that students prioritized the following qualities in their ideal instructor: clarity, competence, and relevance.

However, according to Trammell and Adrich (2016), there are individual differences within students that impact individual preferences for lecturers' qualities. Their results suggest few differences within and between their two groups of students (first-generation college students and non-first generation college students). Students have unrealistically high expectations for lecturers, which is unlikely for lecturers to meet all expectations, resulting in leaving students disappointed or unsatisfied with the programme (Trammell \& Adrich, 2016). What follows is an exploration of students' assessment preferences.

\section{Assessment/coursework preferences}

Competence-based education, together with various assessment methods are being implemented in many institutions of higher vocational education in order to capture the competence development (Baartman et al., 2013). Such a system should reduce the gap between what students learn in the institution to what is needed in the workplace. According to Griffith and Guile (2003), employers look for reflective practitioners that possess an adequate knowledge base in order to solve complex problems. In addition, these employers also want individuals to develop and acquire new knowledge in order to enhance in their career. However, assessment preferences pertaining to higher vocational students need yet to be identified, especially since assessment has an important impact on the students' learning. 
Pereira et al. (2016) have investigated students' perceptions about assessment, especially how it is put to practice. Their findings indicated that students had similar ideas about assessment. Most students responded that assessment is the verification of knowledge and learning. Birenbaum (2007) investigated the relationship between test anxiety and learning strategies with assessment preferences of undergraduate students. The results show that assessment preferences varied between students. The role of learning environments in quality teaching will be discussed next.

\section{The Role of Learning Environments in Quality Vocational Teaching}

Vocational education needs to teach students to integrate knowledge, skills and attitudes (Baartman \& de Bruijn, 2011) whilst simultaneously developing a professional identity (Geijsel \& Meijers, 2005). Two important learning environments to acquire and integrate these types of knowledge, skills and attitudes are vocational colleges and workplaces which provide an environment for authentic learning (Gulikers et al., 2008) and self-direct learning (Kicken et al., 2008). Authentic learning is considered to be learning through the application of knowledge in realistic contexts. Therefore, authentic learning makes use of authentic tasks where the assignments given to students are taken from vocational practice (de Bruijn \& Leeman, 2011). Authentic learning within VET is considered to be effective learning. Such an environment is called a 'powerful learning environment' (PLE). PLE is defined as a learning environment which stimulates growth, bring learners just a little further than they might manage on their own power (de Bruijn, 2012, p. 643). Within a PLE, students ought to be allowed to optimally develop their own competencies, not only for career related problems, but also for their own personal development. Indeed, according to Griffiths and Guile (2003), connecting learning between school and the workplace is of utmost importance, as learning is taking place in social practices to allow students to develop their vocational identity and expertise.

Placklé et. al (2014) aimed to study and investigate what students prefer with regard to the design of the learning environment within the secondary vocational education context. They developed an instrument to measure secondary vocational students' preferences on characteristics of powerful learning environments (PLE) in vocational education. Findings indicate that the preferences of these students support most characteristics of PLE within vocational education. Additionally, it was concluded that teachers have to challenge their students and encourage them to take ownership of their own learning. development. The following section will discuss the theoretical model of powerful learning environments. 


\section{Powerful Learning Environments Framework}

This paper uses this model as a preliminary tool to aid in the decision making process for data collection with regard to the second research question. This research will investigate how the stakeholders in this study respond to the characteristics of PLEs

The concept of PLEs was introduced by De Corte (1990), who refers to learning environments that are designed in a way which foster the necessary learning process to achieve the desire learning outcomes (De Bruijn et al., 2005; De Corte 1990). De Bruijn and colleagues (De Bruijn and Leeman, 2011; De Bruijn and Overmaat, 2002; De Bruijn et al., 2005) constructed a model of powerful learning environments for vocational education. This was a result of previous research projects on competence-based vocational courses in various disciplines such as business administration, health care and technology.

The aim of PLEs was inspired by sociocultural theory in order to develop the vocational identity (Billett, 2001). The model of PLE comprises a mix of traditional features such as instruction, active and reflective learning. The features used in the study are:

1. Programme characteristics:

a) Vocational identity is formed as the starting point of learning

b) Authentic learning

c) Learning programmes should be designed in a manner where constituent parts such as theory and practice relate to each other

2. Learning activities of students:

a) Meaningful, flexible knowledge, and skills should be developed by students for competent professional behaviour. With an authentic and challenging curriculum, constructive learning is stimulated

b) Students develop an autonomous work attitude and vocational habitus through reflective learning, which is achieved when students reflect on their learning and work related experiences with peers and lecturers

3. Guiding activities of teachers should:

a) provide adaptive instruction and act as a role model with regard to the acquisition of vocational knowledge and experience,

b) coach students by critically guiding them in an explorative, reflective and cooperative learning manner, and

c) help students to develop and sustain self-discipline and motivation.

The following section will describe the research design and methodology together with the methods that have formed this study. 


\section{Research Design and Methodology}

Due to the inquirys exploratory nature, an interpretivist approach was used, and in particular a constructivist grounded approach using qualitative data. In the above reviewed literature, the methods used to collect data are mainly of both qualitative and quantitative nature. Furthermore, a recent shift away from monomodality in 'Western' culture was pointed out by Kress and van Leewen (2001). A cultural emphasis on textual practices with more importance placed on text-based genres was dominated in the past. They argue that this approach has begun to shift, and multimodality is making its appearance in various documents and other types of social practices.

One important element in this process has been the gradual ascendancy of the screen over the book as the predominant mode of presentation in many spheres of life, bringing with it a greater emphasis on non-textual images and visual layout. (Gourlay, 2010, p. 80)

However, although higher education communication has shifted to the screen and involves the visual and multimodal aspect of communication, there is a scarcity of research considering the visual and multimodal aspects of higher education teaching and learning. This is also the case with studies applying visual research methods to investigate teaching-learning as a complex multimodal practice, in particular in relation to vocational education. A unique approach of data gathering was used in this study. This involved a qualitative approach consisting of semi-structured photo-elicitation interviews.

\subsection{Participants and Sample Size}

A purposive approach to multiple case study selection was used where the unit of analysis was a higher vocational student. For the purposes of this study, students had to be enrolled in an undergraduate vocational degree programme. For the purposes of this study, students had to be enrolled in an undergraduate vocational degree programme. As a vocational lecturer employed in Malta's main vocational college, and having an emic perspective within this study, I decided to invite (via e-mail) all first year and final year students in two institutes within the university college, outside of the institute I work in. This approach increases the validity of the research project and omits bias. A total of ten participants from two different institutes within the vocational university college agreed to be interviewed. There were four first year students that did not reply to my e-mail and hence did not participate in this study. Five first-year Bachelor's degree students were studying at the institute of Applied Science, whilst the other five participants were in their final year of their Bachelor's degree, studying at the institute of Engineering and Transport.

The participants of this study are nine males and one female: Adrian, Bernard, Charles, David, Edward, Francis, Gareth, Hubert, Ian and Jane (all pseudonyms). Five of them happened to be a whole group in their final year of engineering. The other five are in their first year of their degree studying within the institute of Applied Science. 
Their ages range from 18 years old and 25 years old. Some of these students joined the vocational college exactly after completing the compulsory education, while others joined the vocational college after spending a year or two at the University of Malta reading for academic degrees. This data was collected during the individual interviews with those who participated in this study, where students were encouraged to give a brief overview of their educational experience after they had completed compulsory education.

\subsection{Methods and Data Collection}

This was carried out at the institute of Engineering and Transport and the institute of Applied Sciences in Malta's main vocational college during the second semester of 2016-2017 academic year. Classical interviewing technique was used to answer the first research question and photo elicitation interview to answer the second research question. Participants were interviewed individually at their respective institute by myself, and were informed that they could withdraw from the interview at any time. Interviews were digitally audio-recorded and transcribed word for word, for data analysis. These transcriptions helped me develop a deeper understanding of the emerging discourse during the semi-structured interviews and the image-reflectivity task. All transcriptions were sent to the participants for their perusal before data analysis. These interviews lasted approximately 45 minutes each. Some of the quotations used in this paper have been translated from Maltese.

The use of visual data may be a powerful mode for the reflexive investigation of preferred learning environments. I have chosen to use photo-elicitation methods for the second research question. A focus on images may provide research participants with a means by which to express complex experiences in an indirect, metaphorical or less threatening way. Prior to the interview, participants were encouraged, to produce an image of their preferred learning environment. This image was then discussed during the interview. The meaning making process and aim was to uncover the hidden aspects of their experiences, which acts as a verification method of the previously discussed questions during the semi-structured interview and to empower participants.

These two methods combined together provided a powerful tool for the participants to think about their perceptions and expectations of vocational teaching-learning, and is also a powerful tool for myself to better understand their thoughts and beliefs.

\subsection{Ethical Considerations}

All educational research guidelines and ethical rules have been followed. Ethical approval from the Head of University College was granted on 3rd March 2017, and participants were given full information pertinent to the study. In addition, participants were assured pseudonyms would be used, and that any comments or quotations used in the published research would be anonymous. 


\subsection{Data Analysis}

Iterative interview analysis

To answer the first research question, and analyse the transcripts of the semi-structured interviews, an iterative analysis derived from Flick's (2002) process was carried out. This analysis was partly thematic and partly content analysis. Data for this method was examined for shared patterns that had developed. The process consisted of the following: re-coding of data; searching; discovering relations, tendencies and patterns; categorising and comparing information.

\section{Photo-elicitation image analysis}

To answer the second research question, visual methods were used via the photo-elicitation interviews. The images that students provided during the semi-structured interviews were analysed along with the transcripts of the image reflectivity task. Analysis of this data was also based on qualitative methods where a constant-comparative method was used to determine patterns or themes in the images (Merriam, 1998). Such a method involves comparing one segment of data with another in order to determine whether there are any similarities or differences. Then, data are grouped together according to the similar dimension (Merriam, 1998). Domains of artifacts were established and thematic categorical patterns were drawn from each domain. These will be discussed next.

\section{Findings}

$R Q$ 1: What are the students' perceptions of effective vocational teaching in terms of: lecturers' behaviour, knowledge and personality characteristics; students' needs and expectations; and assessment/coursework preferences?

For the first research question, participants were first asked to comment on what they understand by the term 'effective'. Most found it hard to explain this, and immediately started mentioning examples of effective teaching and learning. However, their main answer was that since they are vocational students, effective teaching and learning is when they can relate the learning at the college with what they will be practicing in their career. In fact, Hubert mentioned that effective teaching is when teaching is both theoretical and practical. On the other hand, Gareth mentioned that effective teaching is how well students absorb what lecturers teach, irrespective of any particular methods.

\section{Lecturers' behaviour, knowledge and personality characteristics}

After commenting on what effective teaching and learning means to them, they were invited to share their experiences of effective teaching and learning methods. All participants mentioned 'group work'. Adrian stated that:

Yes, I did experience effective teaching and learning. Sometimes working in a group and finding what you need to learn by yourself, it helps me more. If 
the lecturer just explains and the students simply write what is being written on the whiteboard I will surely not learn anything.

Edward mentioned that effective teaching and learning is when a lecturer relates the explanations in class to something in reality, and uses images in presentations to help students visualise. In addition, almost all participants mentioned that they prefer visual learning to text-based learning. Another mentioned method is interactive lectures. Indeed, all prefer lectures to include presentations with more diagrams, images and less text, and who discuss the subject content. All participants disliked formal lectures. They also expressed that they do not like it when lecturers use presentations improperly. David stated that:

I hate it when lecturers just read from the PowerPoint presentation and won't be explaining a thing! I cannot stand it. And then to make matters worse, the voice is a monotone.

Hubert's comment was similar to David's. He finds lecturers reading directly from a book useless. Other methods considered effective were tutorials, student presentations, and tasks given to be worked at home. Ian mentioned that his best effective teaching and learning experience is when he constantly explains and answers students' challenging questions.

Participants were also asked to mention which method they wish to see in every lecture they attend. They all agreed that there is no particular method which they prefer, as long as the lecturer interacts with the students and a discussion is constantly maintained. Equally important, David mentioned that he prefers field work, since it gives him insight on what really involves together with apprenticeship.

They were also invited to comment about a vocational lecturer's good qualities. Most of them mentioned a lecturer having industrial experience, and who can relate the contents of the curriculum with what happens in industry. However, this seemed to be a priority mainly with final year students. First years commented that lecturers should be open and approachable. It was also mentioned that lecturers should be charismatic and show enthusiasm whilst lecturing. Jane, a first-year degree vocational student stated the following:

Lecturer has to be alert and know exactly the state in which students are in during the lesson. They need to know the subject well and adapt teaching to each and every student that is present. .and not to blunt!! It's natural to have preferences but please, don't show it to the students! They should show respect and always be willing to help students.

Final-year students also mentioned that they would want the lecturer to include authentic tasks and provide challenging learning pathways; this would definitely help them in their place of work once they graduate. Other qualities mentioned between both groups was class control, engaging students in learning, being constructive and reflective, help 
them in the formation of their vocational identity, and enhance personal growth.

Assessment/coursework preferences

Having discussed the characteristics of effective vocational teaching-learning, and the qualities of a good lecturer, the participants were invited to comment about their preferred assessment styles. A common answer was assessed home based assignments. All participants agreed that when a subject involves in-depth learning, they prefer to research about a particular topic and be given an assignment about it. Likewise, they stated that exams were their second preference. However, all agreed that certain subjects which require calculation such as maths should be assessed as a time-constrained assignment under examination conditions. They mentioned that this will prevent students from copying. It was only Bernard who mentioned that he prefers oral exams if given the choice. Correspondingly, all agreed that exams which only require memory work without any challenging tasks should never be assessed. Ian, a final-year student, mentioned:

Why should we learn facts and be examined about those facts? There's the big book of facts which one can use! That's purely a waste of time and not examining our capabilities, but testing our memory which is not fair.

In addition, David explicitly said that he does not agree with the idea of exams. He commented:

Exams are important but you don't need an exam to pass. I agree with percentages. So for example $60 \%$ would be for an assignment, $20 \%$ for practical work and the last $20 \%$ for an exam. In that way, you will distinguish the outstanding students from the average students.

Gareth explained that the assessment style solely depends on the subject, and does not mind having exams. He mentioned that this might be so, as exams were almost widely used throughout his formal education years. Likewise, Edward mentioned that the assessment styles he encountered in his student life where the conventional marking scheme, which are exams.

After discussing various assessment styles participants were invited to comment about feedback from lecturers on an assigned task or assessment. All participants agreed that they would be eagerly waiting for feedback. All except Francis mentioned that the feedback style (whether written feedback or verbal feedback) does not make any difference so long as it is timely and fully given. On the other hand, Francis mentioned that he prefers written feedback, especially when it comes to corrections about certain engineering related problems.

Participants were also asked if their preferred assessment style is widely used with the institute they form part: all agreed that it mostly is. 
RQ 2: What are the students' preferred learning environments?

The second research question aimed to identify the preferred learning environments via the use of images that participants provided during the interview. The images provided were organised into five domains of learning environments: 1) representation of group work, 2) representation of practical work, 3) representation of discussion, 4) outside class, and 5) representation of passion for subject content. The image representations of their preferred learning environment varied in style and type. Participants were asked to provide one image, though there were Edward and Ian who provided two images each. While reflecting upon and discussing the images, the importance of the participants own past personal and current experiences together with their beliefs about effective vocational teaching and learning became evident. Each domain is discussed and examples from the students' images are shared to depict the themes within each domain.

Representation of 'group work'

The images of this domain typically reflected the characteristics of effective teaching. Two thematic categories of information came across this data. The participants of the study focused on the personality characteristics of lecturers and to the methodologies used by lecturers. For example, Adrian prefers group work as an effective teachinglearning method. In fact, he said that he chose the image below (Figure 1) as it portrays the desks placed into groups of four. Furthermore, Adrian continued to explain that since gym balls are replacing the chairs, the environment enhances serenity, making the students feel relaxed and motivated.

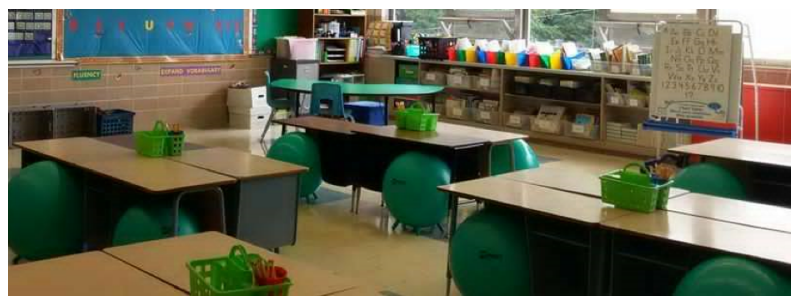

Figure 1: Adrian's preferred learning environment

Bernard, Charles and David chose a similar image between them, although still unique. Their image was of a lecturer showing enthusiasm and interacting with the students during a lesson. Students also seemed to be participating happily and satisfied with the lecture.

\section{Representation of 'practical work'}

The images of this domain reflected the benefits of practical sessions. Three of the finalyear students chose a similar image which was that of a site, particularly in an engine room (Figure 2). Edward, Francis and Gareth mentioned that site visits help them a lot and gives them the opportunity to practice what they do in class. 


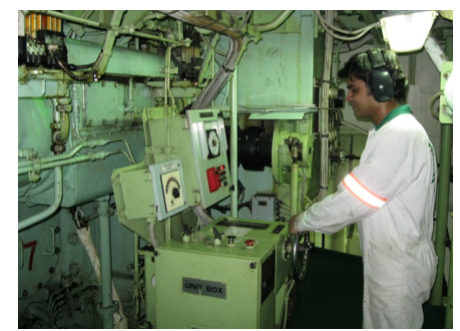

Figure 2: An example of an engine room

\section{Representation of 'discussion'}

Images within this domain reflect how learning can be achieved from discussion. Edward provided a second image depicting a semi-circular set up class as shown below:

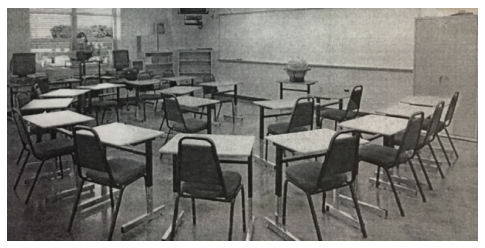

Figure 3: Edward's second image of his preferred learning environment

He commented that a small class with that kind of setup enhances discussion. In addition, he mentioned that he would want to be in this type of class room setup when it comes to subjects that require a lot of calculations such as pure maths. He also stated the following:

I agree with a traditional class room. I don't agree with learning outside, because there are too many distractions. Even when I study, I want to be in a confined space on my own.

Moreover, Ian provided the below image:

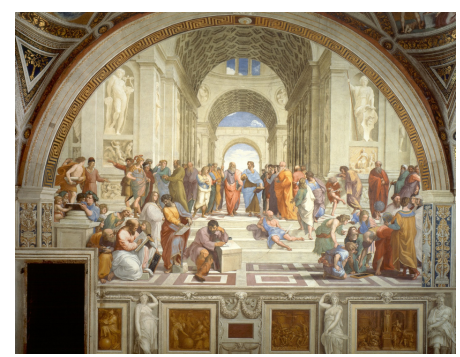

Figure 4: Ian's preferred learning environment 
For Ian, Raphael's 'The School of Athens' involves challenging discussion. His remarks were that the contemporary classroom setup is unfortunately too formal, and does not promote discussion. He expressed his frustration that sometimes education institutions move backwards instead of forward. He continued to explain that education tends to focus on either scientific or artistic disciplines. He stated that:

Art inspires creativity. So why do we eliminate art from our scientific learning. We speak about innovation all the time, yet we do not teach the tools that would help when it comes to creating an innovative idea. The learning system has become too bureaucratic.

We have forgotten that learning is a lifelong experience that is essential for improving our society and not for individual gain. I dare say that schools and universities from my personal experience are just one big power grab! Where the student and the teachers are treated like the lowest life forms.

Outside class

Images for this domain were the fewest in number as it was only Hubert that chose such a preferred learning environment. The image he provided is the following:

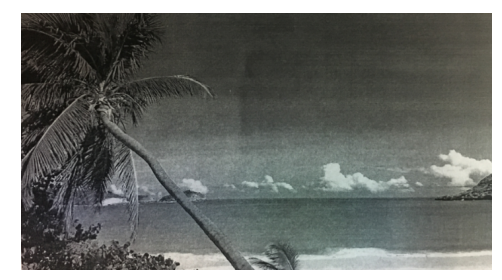

Figure 5: Hubert's preferred learning environment

He commented that he will only learn in a relaxing environment and prefers change. Indeed, he would prefer learning outside the class in a completely new place, which would motivate him more.

\section{Representation of passion for subject content}

Similar to the fourth domain, it was only Jane who provided a diagram. Here, discipline was the main emphasis rather than the lecturer. This is depicted in Image 6 below: Jane discussed that she chose that diagram since it shows the exact flow of how one should learn, which in her opinion, is the best way to learn, irrelevant of any particular teaching methods or good qualities in a lecturer.

\section{Discussion}

This study was designed to examine students' perceptions of effective vocational teaching in terms of lectuers' behaviour, knowledge and personality characteristics; students' 


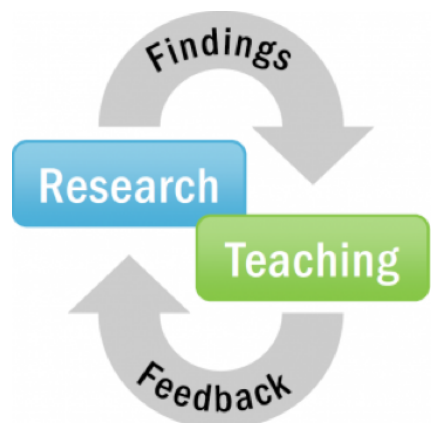

Figure 6: Jane's preferred learning environment

needs and expectations; and assessment preferences. In addition, the second purpose was to investigate students' preferred learning environments.

Regarding the first research question, the findings indicated a difference between firstyear and final-year degree students' perceptions of effective teaching and learning. The findings revealed a difference mainly in the qualities of a good lecturer. Final-year degree students gave importance to lecturers having industrial experience, whereas firstyear degree students expected approachable and charismatic lecturers. Earlier research on personality characteristics also showed this (e.g. Sikorski et al., 2002; Adamson et al., 2005; Faranda \& Clarke, 2004). However, all participants expect lectures to be student-centred and interactive.

Most participants were disappointed in their learning experiences. They stated that some lecturers emphasize more on theory than practice. All vocational students believe that both theory and practice are important. This study's particular results are consistent with previous research on quality teaching within the higher education context (Ustunluoglu, 2017). In addition, Muddiman and Frymier (2009) stated that learning is enhanced when lecturers promote a lively discussion while teaching and relating practice to theory. On the other hand, positive learning experiences that participants commented about were when group work and visual learning are involved. Participants appreciate the fact that the use of visuals are incorporated in their PowerPoint presentations, as they can automatically visualise and relate to what they will find in industry. However, both groups raised their concern about the use of PowerPoint presentations during lectures. They claimed that some of the lecturers do not use them in the most useful way, and lectures end up being too formal and monotonous. Furthermore, all participants do not have a preference with regard to the teaching method, so long as a discussion with the lecturer is maintained throughout.

Participants were concerned with the assessment style. They claimed that every subject should be assessed respectively. All students agreed that they prefer home based assignments. Most also agreed with having split percentages to assess a particular topic. The assessment style would be split up between coursework, practical session and exam. These findings are in line with the studies of Zoller and Ben-Chaim (1988), where students prefer assessments that reduce stress and are easy to take. 
Pertaining feedback, participants explained that it is essential and beneficial to them. They explained that feedback style does not make any difference to them, so long as it is given to them especially on time. These findings are in line with the results of Chickering and Gamson (1987), where prompt feedback is listed as one of the seven principles for good practice with higher education. Similarly, participants agreed that their voice should be heard to enhance their learning experience.

With regard to the second research question, students' preferred learning environments are in line with most characterstics of the PLE framework. Images with the first domain (representation of group work) reflected the characterstics of the first feature of the theoretical framework used in this study. One can notice that the images represent learning programmes are designed in a manner where theory and practice are related to each other. Students expressed their desires to solve authentic tasks with each other's help. This is also in line with the second domain (practical work) of the photo-elicitation interviews. The students' images also depict their want of explorative and reflective learning, the third feature of the PLE framework. Indeed, classroom environments where a discussion can be maintained were chosen as a preference. These findings are in line with the study of Placklé et al., (2014).

\section{Conclusions, Limitations and Future Work}

In an ideal learning environment both students and educators work hand in hand to experience exceptional teaching and learning. Higher vocational students have their own preferences, and giving them a voice and seeing through their eyes is the first step for enhancement to take place. Findings from this study raise important points for consideration within the higher vocational education context. The findings presented indicate that students should be allowed to voice their opinions and their evaluations should be considered. Likewise, lecturers teaching within the higher vocational education context should also voice their opinion and identify their expectations of their lectures too. This will help both lecturers and students become aware of these expectations and preferences, and relevant professional development should be offered to these lecturers to enhance the teaching experience. This study is of interest as it provides a clear idea of what higher vocational students are satisfied with lecturers' abilities, and those in which they are less pleased with. From the evidence of the participants of this study, it can be concluded that there is no particular difference between a higher vocational student and a higher education student. This is so since the characteristics that were mentioned are very similar and consistent to previous research with higher education students (Ustunluoglu, 2017; Sander et al., 2000).

The participants also showed their preferences on the characteristics of powerful learning environments, which is the theoretical framework adopted for this study. In summary, they prefer to be the centre of teaching and learning and having authentic tasks organised for them. They also prefer being given opportunities to develop key competences, have teachers that are adaptive to support their learning, and work within a social practice in order to form their vocational identity. However, implementing PLEs can cause 
tension and dilemmas on teachers. Teachers should be equipped to offer students their support. Having students in class with various preferences to various learning styles would be very difficult for the teacher to accomadate all at once. It is clear that there is inconsistency between the ideal scenario and what happens in practice. Hence, future work should include research on how teachers can cope with such challenges, how a consensus between various students' preferences can be reached and how vocational learning pathways can be redesigned to raise students' engagement and reduce dropouts. Furthermore, future research should also consist of an ideal framework to be considered when preparing authentic tasks, and how such tasks can be evaluated in order for learning to be meaningful.

Consideration of this collected data within this conceptual study could be used as a useful guide for designing and delivering bachelor's degree courses following a cohesive, vocationally oriented pedagogic-didactic approach, where a powerful learning environment is made available. However, the findings and their implications cannot be taken into consideration without highlighting the limitations and shortcomings of this research. These will be discussed next.

In this small scale study, the research design focussed on first year and final year higher vocational students from two different programmes only. Statistical or socioeconomic data was not collected and analysed within this study. It would be insightful to include this data for further research. These participants from two different courses (Engineering and Applied Science) had different academic histories. There were students who joined the vocational college directly after compulsory education, and others who spent a year or two at university. These students who were at university had different advanced level profiles and also different academic backgrounds. Such differences affect the preferences and expectations of effective teaching and learning. Students who were at university might be more confident learning independently and as a result, having an unapproachable lecturer does not affect them. Therefore, such different academic backgrounds may warrant further investigation using the same methodology but also measuring student learning styles. Consequently, it would have been ideal to add to this conceptual study a collection of the details of the various previous experiences of different teaching and learning methods together with assessment styles these participants had. Such additional information would establish the extent of any differences between these participants, and whether there is a relationship between a preference or expectation for a particular teachinglearning method and awareness between them.

It would also be beneficial to conduct a longitudunal conceptual study starting from their first year up to their final year, and monitor changes in their attitudes towards effective vocational teaching and learning. The impact of these additional descriptions could also be considered when choosing professional development programmes for higher vocational lecturers.

When collecting such sensitive data, a range of students' expectations might be identified that for some reason or other might not be met due to various limitations regarding education resources or pedagogical matters. Such information is useful as certain unreasonable expectations will be catered for if planned ahead. Furthermore, such data collection could be an effective means of giving higher vocational students a voice when 
constructing courses, and will guide course team discussions with regard to teaching, learning and assesssment.

\section{References}

Adamson, G., O'Kane, D., \& Shevlin, M. (2005). Students' ratings of teaching effectiveness: A laughing matter? Psychological Reports, 96, 225-226.

Andersen, J. (1979). Teacher immediacy as a predictor of teaching effectiveness. In D. Nimmo (Ed.), Communication yearbook 3 (pp. 543-559). NJ: Transaction Books.

Anderson, L. (2000). Teaching development in higher education as scholarly practice: A reply to Rowland et al. turning academics into teachers. Teaching in Higher Education, 5(1), 23-31.

Baartman, L., \& De Bruijn, E. (2011). Integrating knowledge, skills and attitudes: Conceptualizing learning processes towards vocational competence. Educational Research Review, 6, 125-134.

Baartman, L., Gulikers, J., \& Dijkstra, A. (2013). Factors influencing assessment quality in higher vocational education. Assessment and Evaluation in Higher Education, 38(8), 978-997.

Biemans, H., Nieuwenhuis, L., Poell, R., Mudler, M., \& Wessenlink, R. (2004). Competence based VET in the Netherlands: Background and Pitfalls. Journal of Vocational Education and Training, 56(4), 523-538.

Billett, S. (2001). Knowing in practice: Re-conceptualising vocational expertise. Learning and Instruction, 11, 431-452.

Birenbaum, M. (2007). Assessment and instruction preferences and their relationship with test anxiety and learning strategies. Higher Education, 53, 749-768.

Chickering, A., \& Gamson, Z. (1987). Seven principles for good practice in undergraduate education. Retrieved June 2017, from http://www.lonestar.edu/multimedia/seven principles.pdf

Dahl, K. (1995). Challenges in understanding the learner's perspective. Theory into Practice, 43(2), 124-130.

de Bruijn, E. (2004). Changing pedagogic and didactic approaches in vocational education in the Netherlands: from institutional interests to the ambitions of students. Brussells: CEDEFOP. Retrieved from http://www.cedefop.europa.eu/en/publicationsand-resources/publications/312004

de Bruijn, E. (2012). Teaching in innovative vocational education in the Netherlands. Teachers and Teaching, 18(6), 637-653.

de Bruijn, E., \& Leeman, Y. (2011). Authentic and self-directed learning in vocational education: Challenges to vocational educators. Teaching and Teacher Education, 27, 694-702.

de Bruijn, E., \& Overmaat, M. (2002). Internal effects of powerful learning environments in secondary vocational education. Midterm report requested by PROO.

de Bruijn, E., Overmaat, M., Glaude, M., Heemskerk, I., Leeman, Y., Roeleveld, J., \& Van de Venne, L. (2005). Powerful Learning Environments in secondary vocational 
education: Design and effects. Pedagogische Studien, 82, 77-96.

de Corte, E. (1990). Towards powerful learning environments for the acquisition of problem solving skills. European Journal of Psychology of Education, 5(1), 5-19.

Dwyer, C. (2001). Linking research and teaching: A staff-student interview project. Journal of Geography in Higher Education, 25, 357-366.

Faranda, W., \& Clarke, I. (2004). Student observations of outstanding teaching: Implications for marketing educators. Journal of Marketing Education, 26(3), 271-281.

Flick, U. (2002). An introduction to qualitative research. London, UK: Sage.

Frymier, A. (1994). A model of immediacy in the classroom . Communication Quarterly, $42,133-144$.

Frymier, A., \& Shulman, G. (1995). "What's in it for me?": Increasing content relevance to enhance students' motivaiton. Communicaiton Education, 44, 40-50.

Geijsel, F., \& Meijers, F. (2005). Identity learning: The core processes of educational change. Educational Studies, 31, 419-430.

Goldman, Z., Cranmer, G., Sollitto, M., Labelle, S., \& Lancaster, A. (2017). What do college students want? A prioritization of instructional behaviours and characteristics. Communication Education, 66(3), 280-298.

Gourlay, L. (2010). Multimodality, visual methodologies and higher education. In M. Savin-Baden, \& C. Howell Major, New approaches to qualitative research: Wisdom and Uncertainty (p. 80). London and New York: Routledge.

Griffith, T., \& Guile, D. (2003). A Connective Model of Learning: The Implications for Work Process Knowledge. European Educational Research Journal, 2, 56-73.

Gulikers, J., Bastiaens, T., Kirschner, P., \& Kester, L. (2008). Authenticity is in the eye of the beholder: Student and teacher perceptions of asssssment . Journal of Vocational Educaiton and Training, 60, 401-412.

Hara, N. (2000). Student distress in a web-based distance education course. Information, Communication \& Society, 3(4), 557-579.

Hatakenaka, S. (2006). Higher Education in Turkey for 21st century: Size and Composition. Retrieved June 2017, from http://siteresources.worldbank.org/EXTECAREG TOPEDUCATION/Resources/444607-1192636551820/S._Hatakenakas_report_on_H: gher_Education_in_Turkey_for_21st_Century_Nov_2006.pdf

Henard, F. (2010). Learning our lessons: Quality teaching in higher education. Paris: OECD.

Hill, F. (1995). Managing service quality in higher education: the role of the student as primary consumer. Quality Assurance in Education, 3, 10-21.

Hounsell, D. (2003). Student feedback, Learning and Development. In M. Slowey, \& D. Watson (Eds.), Higher education and the lifecourse (pp. 67-78). SRHE \& Open University Press.

Houser, M. (2005). Are we violating their expectations Instructor communicaiton expectations of tradational and nontraditional students. Communication Quarterly, $53,213-228$.

Jaasma, M., \& Koper, R. (1999). The relationship of student-faculty out-of-class communication to instructor immediacy and trust and to student motivation. Communication Education, 48(1), 41-47. 
Kicken, W., Brand-Gruwel, S., \& Van Merrienboer, J. (2008). Scaffolding advice on task selection: A safe path toward self-directed learning in on-demand educaion. Journal of Vocational Educaiton and Trianing, 60, 223-239.

Kress, G., \& van Leewen, , T. (2001). Multimodal Discourse: The modes and media of contemporary communication. London: Hodder Arnold.

McCroskey, J., \& Young, T. (1981). Ethos and credibility: The construct and its measurement after three decades. Communication Studies, 32, 24-34.

Merriam, S. (1998). Qualitative research and case study applications in educaiton. San Francisco: Jossey-Bass.

Misbah, Z., Gulikers, J., Maulana, R., \& Mulder, M. (2015). Teacher interpersonal behaviour and student motivation in competence0based vocational education: Evidence from Indonesia. Teaching and Teacher Education, 50, 79-89.

Muddiman, A., \& Frymier, A. (2009). What is relevant? Student perceptionsof relevance strategies in college classrooms. Communication Studies, 60, 130-146.

Pepe, J., \& Wang, M. (2012). What instructor qualities do students reward? College Student Journal, 46(3), 603-614.

Pereira, D., Niklasson, L., \& Flores, M. (2016). Students' perceptions of assessment: a comparative analysis between Portugal and Sweden. Higher Education, 73, 153-173.

Placklé, I., Konings, K. D., Jacquet, W., Struyven, K., Libotton, A., van Merrienboer, J. J., \& Engels, N. (2014). Students' Preferred Characteristics of Learning Environments in Vocational Secondary Education. International Journal for Research in Vocational Education and Training (IJRVET), 1(2), 107-124.

Rocca, K. (2009). Participation in the college classroom: The impact of instructor immediacy and verbal aggression. Journal of Classroom Interaction, 43, 22-33.

Sander, P., Stevenson, K., King, M., \& Coates, D. (2000). University Students' Expectations of Teaching. Studies in Higher Education, 25(3), 309-323.

Shea, P., Pickett, A., \& Pelz, W. (2003). A follow up investigation of "teaching presence" in the SUNY Learning Network. Journal of Asynchronous Leanring Networks, 7(2), $61-80$.

Sikorski, J., Rich, K., Saville, B., Buskist, W., Drogan,, O., \& Davis, S. (2002). Student use of introductory texts: Comparative survey findings from two universities. Teaching of Psychology, 29(4), 312-313.

Telford, R., \& Masson, R. (2005). The congruence of quality values in higher educaiton. Quality Assurance Education, 13(2), 107-119.

Trammell, B., \& Aldrich, R. (2016). Undergraduate Students' Perspectives of Essential Instructor Qualities. Journal of the Scholarship of Teaching and Learning, 16(1), $15-30$.

Ustunluoglu, E. (2017). Teaching quality matters in higher education: a case study from Turkey and Slovakia. Teachers and Teaching, 23(3), 367-382.

Verhaeghe, G., Vanhoof, J., Valcke, M., \& Van Petegem, P. (2011). Effects of support of the use of school feedback. Pedagogische Studien, 88(2), 90-106.

Voss, R., Gruber, T., \& Szmigin, I. (2007). Service quality in higher education: The role of student expectations. Journal of Business Research, 60, 949-959.

Witt, P., Wheeless, I., \& Allen, M. (2004). A meta-analytical review of the relationship 
between teacher immediacy and student leanring. Communication Monographys, $71,184-207$.

Zoller, U., \& Ben-Chaim, D. (1988). Interaction between examination-type anxiety state, and academic achievement in college science; An action-oriented research. Journal of Research in Science, 26, 65-77.

\section{Biographical Notes}

Ing. Alison Said is a warranted engineer by profession and is a lecturer within a vocational institution in Malta. She is currently a doctoral candidate in Higher Education and her main research interests focus on vocational teaching and learning, higher vocational education and professional identities. 